\title{
Bowel Injury following Illegal Abortion : An Unusual Case
}

\author{
SESHADRI LN ${ }^{1}$, PREETHI B REDDY ${ }^{2}$, TANVEER USTAD HUSSAIN ${ }^{3}$, ARUN B KILPADI $^{4}$
}

\begin{abstract}
:
A rare and life threatening complication of induced abortion is bowel injury. Bowel resection with exteriorization of bowel with possibility of permanent stomas is the treatment, especially when the patient presents late. A 26 year old woman presented with peritonitis and fecal discharge per vaginum 1 week after an illegal abortion. Laparotomy revealed uterine perforation and colonic injury with the fetal head retained intraperitoneally .
\end{abstract}

\section{Case presentation:}

A 26 year old literate woman, mother of 2 girls, hailing from a village of Ananthpur district, Andhra Pradesh presented with history of fecal discharge per vaginum since 2 days and severe diffuse abdominal pain of 1 day duration. She also gave history of constipation since 8 days. Patient had undergone illegal abortion for a 18 week gestation 7 days back after ultrasound revealed a female fetus. Instrumental evacuation was performed by a unqualified rural 'medical practitioner' . On examination, she was pale, tachypnoeic, tachycardic and had mild fever. Per abdomen , there

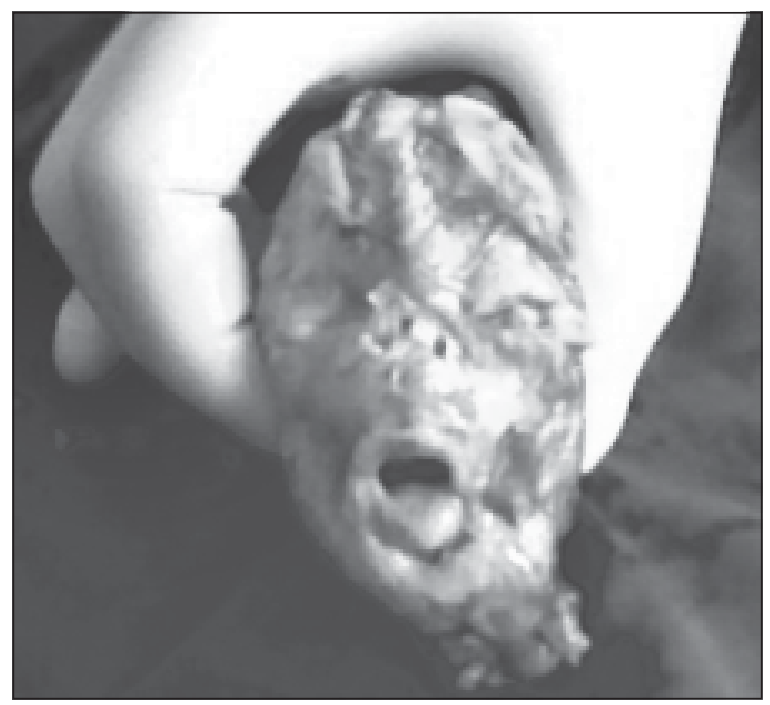

Fig.-1: was diffuse tenderness, with lower abdominal guarding and rebound tenderness. On Per vaginal examination, feculent discharge was present, the cervix was soft, the uterus was bulky and there was fornical tenderness. A firm mass was felt through the left fornix. Per rectal examination revealed nothing significant.

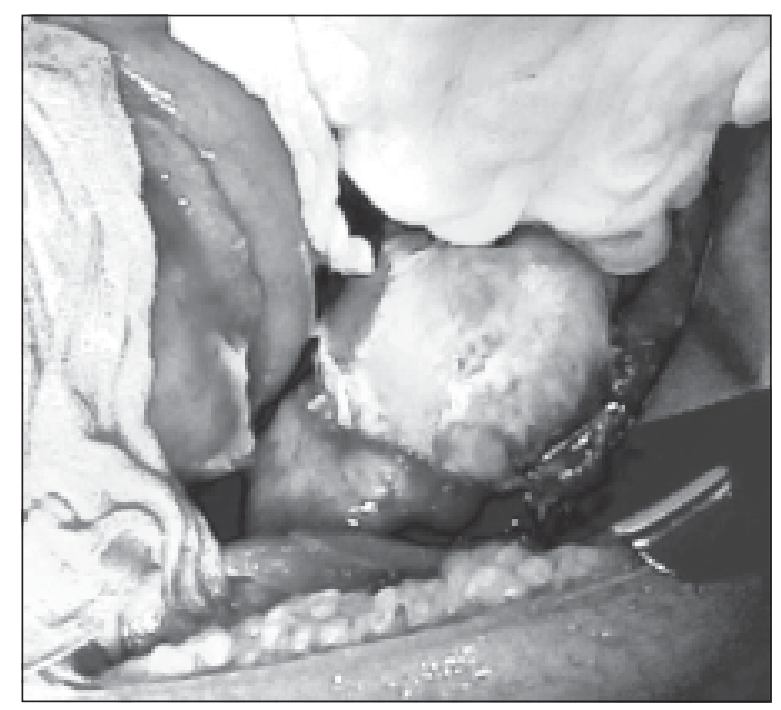

Fig.-2:

Provisional diagnosis was Peritonitis secondary to Uterine perforation and Bowel injury . Exploratory Laparotomy revealed gross fecal peritoneal contamination with $8 \times 6 \mathrm{~cm}$ laceration of the posterior surface of the uterus with near total transection of the

\footnotetext{
1. Postgraduate Resident

2. Intern

3. Lecturer

4. Professor
}

Department of General Surgery, St. John's Medical College Hospital, St.John's National Academy of Health Sciences, Bangalore 


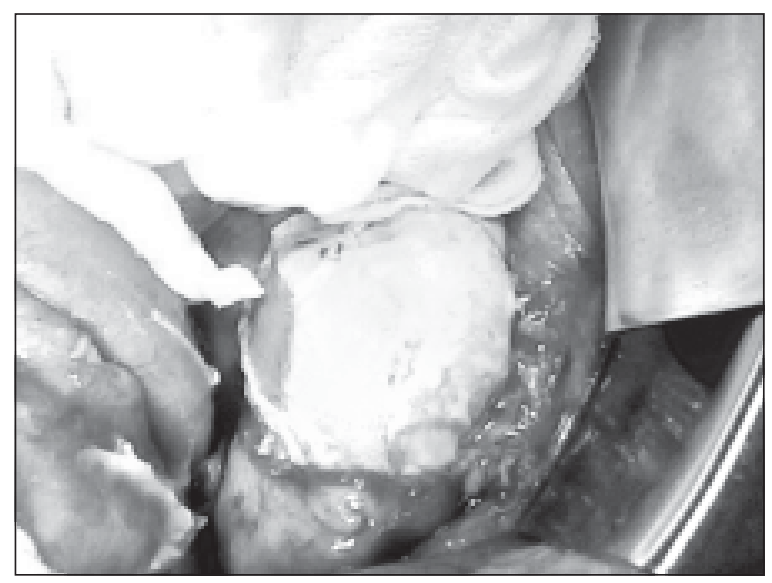

Fig.-3:

rectosigmoid colon with intraperitoneal retained fetal head. Hysterectomy, Hartmann's procedure and peritoneal lavage alongwith removal of the fetal head

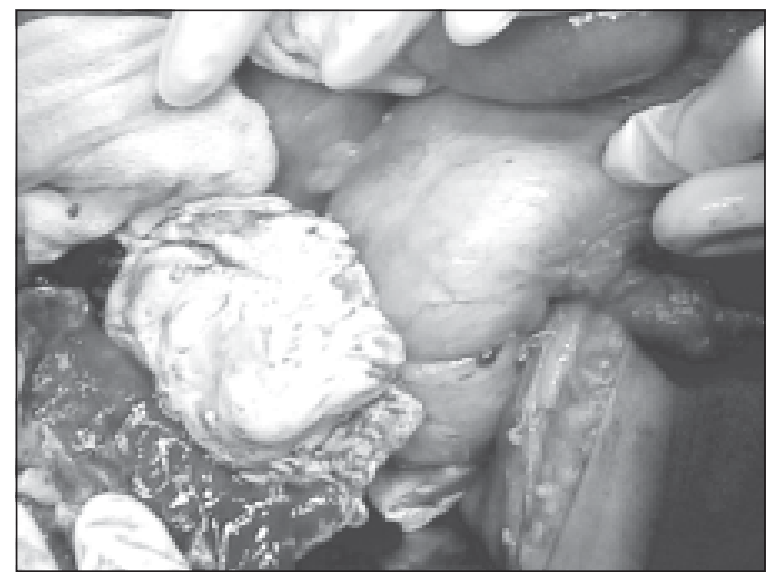

Fig.-4:

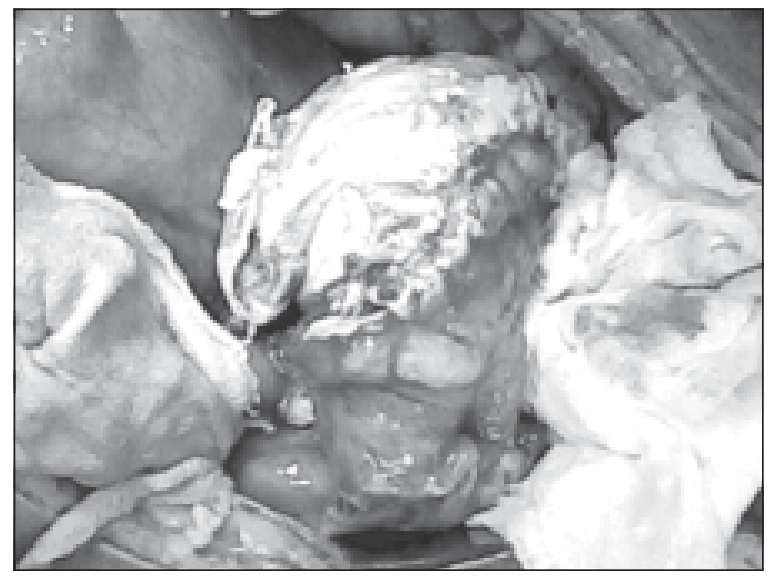

Fig.-5: was performed. Immediate post operative period was uneventful and patient recovered and was discharged with colostomy after one week. After 4 months patient underwent successful stoma reversal with colorectal side to side stapled anastomosis.

\section{Discussion:}

A rare and life threatening complication of induced abortion is bowel injury. The preference for male children, illiteracy, low socioeconomic status, proliferation of prenatal ultrasonic sex determination, poor accessibility for medical facilities and abortion performed illegally by persons without any medical training are important contributing factors. The terminal ileum and pelvic colon are the most commonly injured portions of the bowel owing to their anatomic locations. Ensuing peritonitis and sepsis result in a life threatening condition. ${ }^{[1,2]}$ Bowel resection with exteriorization of bowel with possibility of permanent stomas is the treatment, especially when the patient presents late. The Hartmann's procedure is a time tested method in dealing with left colonic emergenices and still the treatment of choice, specially in sick patients. ${ }^{[3,4]}$ This case is unusual as the fetal head was retained intraperitoneally. We did not come across any similar report in published literature.

\section{References:}

1. Coffman S. Bowel injury as a complication of induced abortion: a case report and literature review. Am Surg. 2001 Oct;67(10):924-6.

2. Jhobta RS, Attri AK, Jhobta A. Bowel injury following induced abortion. Int J Gynaecol Obstet. 2007 Jan;96(1):24-7

3. Georgiadis NJ. Intraperitoneal injuries of the rectum and rectosigmoid encountered in civilian practice. Diseases of the Colon \& Rectum. Volume 7, Number 5 / October, 19644.

Engledow AH, Bond-Smith G, Motson RW, Jenkinson A. Treatment of left-sided colonic emergencies: a comparison of US and UK surgical practices. Colorectal Dis. 2009 Jul;11(6):642-7. 